\title{
Structural, Morphological, Optical and PL Studies of Neodymium Doped ZnS Glass Plate by Nebulizer Spray Pyrolysis Method
}

\author{
A. Jesu Jebadev ${ }^{1}$, M.Karunakaran ${ }^{2} *$ K. Deva Arun Kumar ${ }^{3}$, S.Valanarasu ${ }^{4}$ \\ ${ }^{1,2}$ Department of Physics, Alagappa Government Arts College, Karaikudi, India- 630003 \\ ${ }^{3,4}$ Department of Physics, Arul Anandar College, Karumathur, India - 625514 \\ "Corresponding Author: tvdkaruna@gmail.com, Tel.: +91-8122841591
}

Available online at: www.isroset.org

Received: 18/Apr/2019, Accepted: 12/May/2019, Online: 30/Jun/2019

\begin{abstract}
Herein we have present the preparation of $\mathrm{Nd}$ doped $\mathrm{ZnS}$ thin films on glass substrate by simple nebulizer spray pyrolysis (NSP) method at $450{ }^{\circ} \mathrm{C}$. XRD, SEM, and UV-Vis Spectrometer were used to analyze the Structural, morphological, and optical behavior of the prepared samples. Nature of polycrystalline hexagonal structure with no secondary phases was confirmed by X-ray analysis. Extra particle creation on the surface of the $\mathrm{Nd}$ doped thin film was observed in high magnified SEM images. Room temperature PL studies depicts that the luminance behavior of the parent sample was enormously changed during the $\mathrm{Nd}$ element interstitial with $\mathrm{ZnS}$ lattice. Optical band gap value varies from $3.51 \mathrm{eV}$ to $3.58 \mathrm{eV}$ for $3 \% \mathrm{Nd}$ doped $\mathrm{ZnS}$ film ascribed the increasing of film thickness and diminishing of film transparencies.
\end{abstract}

Keywords - Rare earth, Thin film, Nebulizer spray pyrolysis, Photoluminescence, Band gap.

\section{INTRODUCTION}

Naturally, II-VI based semiconductor with wide direct band gap $\left(\mathrm{E}_{\mathrm{g}}=3.67 \mathrm{eV}\right)$ of $\mathrm{ZnS}$ has Luminescence behavior and it is used as a photo catalyst for a long time. Besides the contribution of $\mathrm{CdS}$, toxic free $\mathrm{ZnS}$ have many Opto electronic applications such as , UV light emitting diodes, sensors , Modulators [1] etc., In addition, it act as a good reflector and dielectric filter [2]. Meanwhile, additions of transition or rare earth metal in $\mathrm{ZnS}$ were arising new kinds of pictures in luminescence recently. Even though, there are many reports available on transition metal doped like Mn, $\mathrm{Cu}, \mathrm{Al}, \mathrm{Pb}$ etc., and their co-doped $\mathrm{ZnS}$ thin film, only countable numbers of papers behind on rare earth metal doping. The main reason regarding on this lack may be expensive and unavailability of rare earth material. At the same time we should concern their unique behavior when doped with any host lattice. Because, some trivalent rare earth ions change vigorously in parent lattice structure and their optical behavior than transition metal. So, herein we synthesized rare earth $\mathrm{Nd}$ doped $\mathrm{ZnS}$ film and characterized their behavior using various parameters.

Core $\mathrm{ZnS}$ thin film was prepared by various techniques such as SILAR [3], Sputtering [4], Electro deposition [5] , ALE [6], CBD [7], CVD [8] spray pyrolysis [9] etc., Apart from these, herein we tried to attempt on making homogeneous transparent thin film by simplest NSP techniques.NSP is a kind of Spray technique and it is low cost and more suitable for large scale thin film preparation.

\section{MATERIALS AND METHODS}

Thin films of host and $\mathrm{Nd}$ doped $\mathrm{ZnS}$ were prepared with analytical grade Zinc chloride $\left[\mathrm{ZnCl}_{2}\right]$, Thiourea $\left[\mathrm{CH}_{4} \mathrm{~N}_{2} \mathrm{~S}\right]$ and Neodymium acetate monohydrate $\left[\mathrm{Nd}\left(\mathrm{CH}_{3} \mathrm{COO}\right)_{2} \cdot \mathrm{H}_{2} \mathrm{O}\right]$ (purchased from Sigma-Aldrich and Alfa Aeser) by NSP technique. To remove any impurities, glass substrates were cleaned by hot chromic acid, de-ionized water, and acetone. For a parent precursor solution $0.2 \mathrm{M}\left(\mathrm{ZnCl}_{2}\right)$ and $0.2 \mathrm{M}\left(\mathrm{CH}_{4} \mathrm{~N}_{2} \mathrm{~S}\right)$ were dissolved into $10 \mathrm{ml}$ (Isopropyl alcohol and de-ionized water with 3:1 ratio) solvent and stirred well for $10 \mathrm{~min}$. To make 3 $\% \mathrm{Nd}$ doped film, neodymium acetate monohydrate $[\mathrm{Nd}$ $\left.\left(\mathrm{CH}_{3} \mathrm{COO}\right)_{2} \cdot \mathrm{H}_{2} \mathrm{O}\right]$ was dissolved in the prepared parent solution and adding of three drops of $\mathrm{HCl}$ make clear homogeneous solution. These solutions were taken in a nebulizer container of volume $10 \mathrm{ml}$ and sprayed with Carrier gas pressure of 1.5 $\mathrm{Kg} / \mathrm{cm}^{2}$ on the heated $\left(450{ }^{\circ} \mathrm{C}\right)$ glass substrate (located at $25 \mathrm{~mm}$ from the nozzle) continuously to get a uniformly smooth film. 
The Structural properties studied by XPERT SOFTWAR using $\mathrm{CuK} \alpha(\lambda=1.5406 \mathrm{~nm})$ radiation. Morphological view of the film was assessed by SEM (Hitachi S-3000H). Transmission and band gap values were analyzed by Shimadzu (UV-3101PC) spectrophotometer. Stylus profile meter (Mitutoyo SJ-301) was used to find the thickness of the Nd:ZnS films. Photoluminescence (PL) were recorded using Perkin Elmer LS55 florescent spectrophotometer.

\section{RESUlTS AND DISCUSSION}

\section{XRD Analysis}

Fig.1 shows the XRD patterns of $\mathrm{Nd}: \mathrm{ZnS}$ thin films. Obtained films have polycrystalline hexahonal structure and matched with JCPDS file No:89-2739.In addition, they have no any other secondary peaks due to neodymium or neodymium oxide when rare earth element was doped with host lattice. From the XRD, it clearly reveals that the high intense peak of pure $\mathrm{ZnS}$ is orient along the (102) plane and there is some low intense peak present along (101), (103), (108), (109) and (116) planes. However, when Nd element doped with host $\mathrm{ZnS}$, intensity of the reflection peaks decreases,indicates that decresing of crystaline size or incresing of crystal lattice imperfection owing to the higher ionic radius of $\mathrm{Nd}^{3+}(0.98 \AA)$ was not perfectly fit with host $\mathrm{Z}$ nS lattice of low ionic radius $\mathrm{Zn}^{2+}(0.74 \AA)$. These results were matched with previous report [10] for $\mathrm{Al}$ doped $\mathrm{ZnS}$ thin films and confirmed in our SEM image.Moreover, the cystalline size calculated by debye scherer formula [11].

$$
D=\frac{0.9 \lambda}{\beta \cos \theta}
$$

and crystal imperfections such as dislocation density $(\delta)$ and micro strain $(\varepsilon)$ calculated with Williamson and tangent relations [11].

$$
\begin{aligned}
\varepsilon & =\frac{\beta \cos \theta}{4} \\
\delta & =\frac{1}{D^{2}}
\end{aligned}
$$

from our XRD data Confirmed the same results.

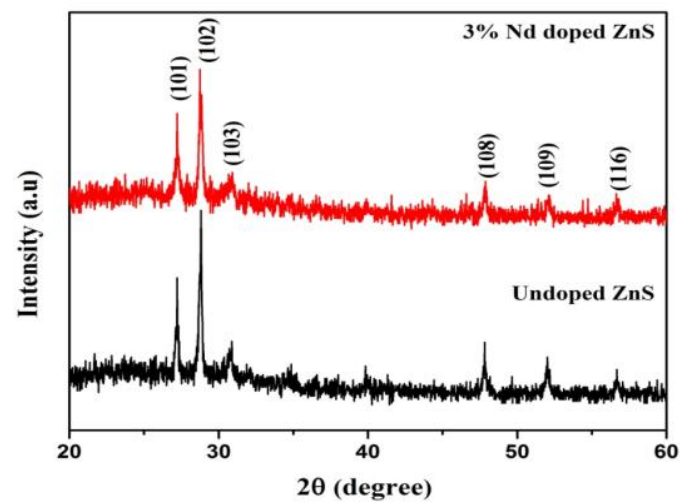

Figure 1. XRD patterns of Undoped and 3\% $\mathrm{Nd}$ doped $\mathrm{ZnS}$ thin film In addition, we have calculated the lattice parameters ' $a$ ' and ' $c$ ' of the films by the following relations [12].

$$
\frac{1}{d^{2}}=\frac{4}{3}\left\{\frac{h^{2}+h k+k^{2}}{a^{2}}\right\}+\left\{\frac{l^{2}}{c^{2}}\right\}
$$

Where, all constants have their usual meanings. The decrement of value of lattice parameters when $\mathrm{Nd}$ ions doped with $\mathrm{ZnS}$ means changing of crystal growth orientation and evidenced by our XRD intensity variation plot and same result was obtained for K.D.A. Kumar et al [13] when $\mathrm{Nd}$

\begin{tabular}{|c|c|c|c|c|c|}
\hline \multirow{2}{*}{$\begin{array}{c}\mathrm{Nd} \\
\text { doping } \\
\text { level } \\
(\%)\end{array}$} & \multirow{2}{*}{$\begin{array}{l}\text { Crystallite } \\
\text { size }(\mathrm{nm})\end{array}$} & \multirow{2}{*}{$\begin{array}{c}\text { Dislocation } \\
\text { density } \\
\left(\times 10^{15}\right) \mathrm{nm}^{-2}\end{array}$} & \multirow{2}{*}{$\begin{array}{l}\text { Strain } \\
(\text { lines } \\
{ }^{2} \cdot m^{-4} \text { ) }\end{array}$} & \multicolumn{2}{|c|}{ Lattice Constant } \\
\hline & & & & $a=3.812$ & 8.690 \\
\hline 0 & 55 & & & 38 & 18. \\
\hline 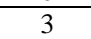 & 51 & 0.377 & .0027 & 3.77 & 18.692 \\
\hline
\end{tabular}
doped with $\mathrm{SnO}_{2}$. All structural parameters were tabulated given below.

Table 1. The structural parameters and lattice constants of prepared samples

\section{Morphological Studies by SEM}

High magnified SEM images shown surface morphology of Pure (fig 2a) and 3\% Neodymium (fig $2 \mathrm{~b}$ ) doped $\mathrm{ZnS}$ thin films. SEM image of the undoped film visualize that they are homogeneous nature with spherical grains in nanometer range. Whereas, when $\mathrm{Nd}$ element was doped with parent film ,it is a results of creation of extra particle accumulation on the host lattice; which ascribed the higher ionic radius of $\mathrm{Nd}^{3+}$ ions couldn't incorporate well to the lower ionic radius of $\mathrm{Zn}^{2+}$ ions in host lattice and makes some imperfection and increment of film thickness. Defects calculation made from XRD data and thickness measurement from Stylus profile meter confirms the above results.

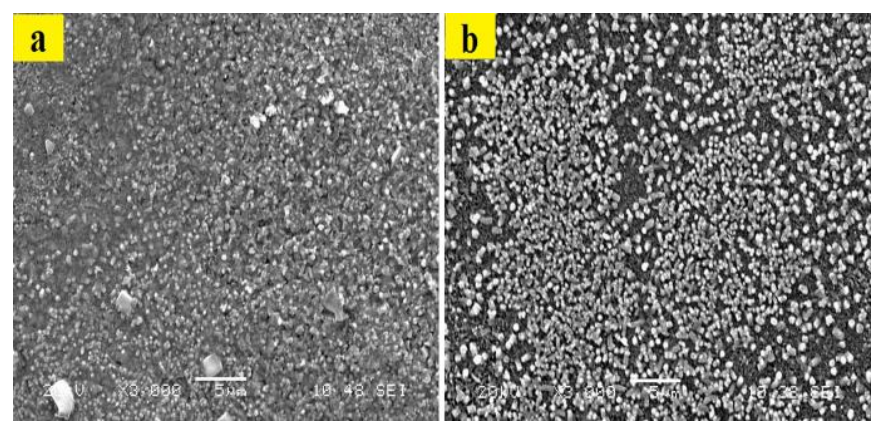

Figure 2. SEM images of a) Undoped and b) 3\% Nd doped $\mathrm{ZnS}$ thin film

\section{Optical Spectra}

Transmittance spectra of synthesized films were portrayed in fig.3. It is seen that the transparency of film decreases when $\mathrm{Nd}$ element interstitial with $\mathrm{ZnS}$ lattice; which means that scattering of photons increment when thickness of the film increases [14] and it is confirmed by SEM images. 
Using absorption coefficient $(\alpha)$, Optical band gap $(E g)$ of the prepared films was determined by the Tauc's formula [12].

$$
\alpha h v=\mathrm{B}\left(\mathrm{h} v-\mathrm{E}_{\mathrm{g}}\right)^{\mathrm{n}}
$$

Here, $(\mathrm{h} v)$ is the incident photon energy, and $(B)$ is constant value. Pure and $3 \% \mathrm{Nd}$ doped $\mathrm{ZnS}$ film have band gap of value 3.58 and $3.62 \mathrm{eV}$ and they are shown in Fig.4. The average of this band gap value is very close to the value of bulk $\mathrm{ZnS}(3.60 \mathrm{eV})$ material and previous report [15].

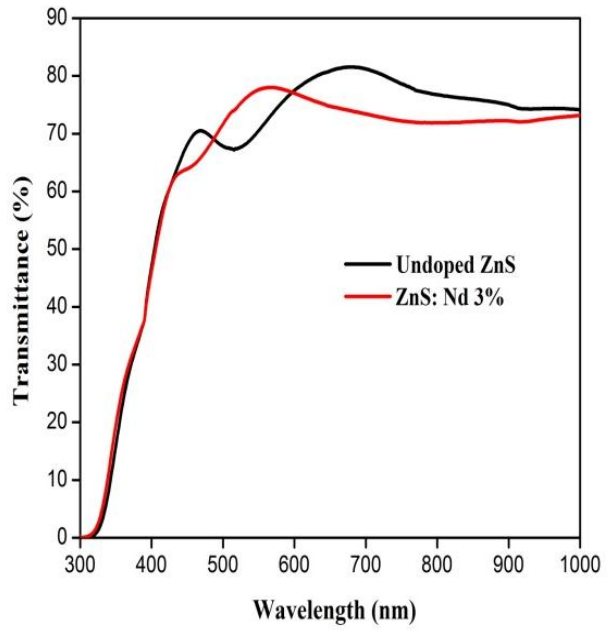

Figure 3. Transmittance spectrum

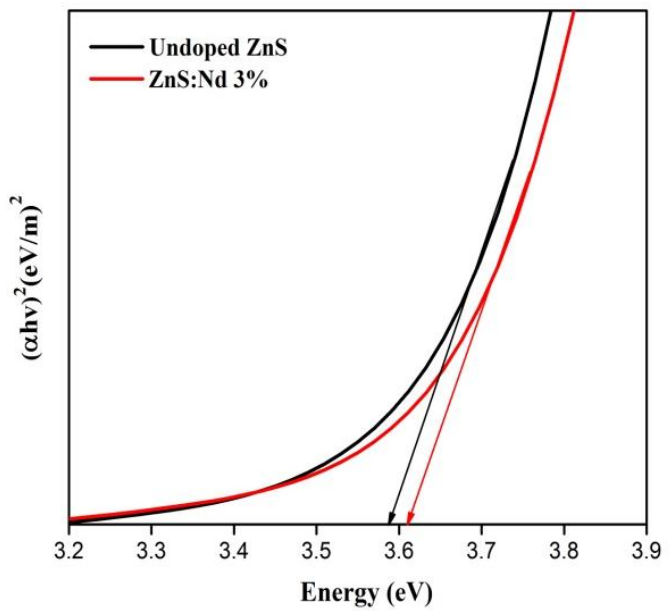

Figure 4 .Band gap variations

Table 2 shows the values of transparencies, thickness and band gap of the $\mathrm{Nd}: \mathrm{ZnS}$ thin films.

Table 2. The value of optical transmittance, thickness and band gap of the prepared samples

\begin{tabular}{|c|c|c|c|}
\hline $\begin{array}{c}\text { Nd doping level } \\
(\boldsymbol{\%})\end{array}$ & $\begin{array}{c}\text { Transmittance } \\
(\boldsymbol{\%})\end{array}$ & $\begin{array}{c}\text { Thickness } \\
(\mathbf{n m})\end{array}$ & Band gap $(\boldsymbol{e V})$ \\
\hline 0 & 83 & 230 & 3.58 \\
\hline 3 & 78 & 302 & 3.62 \\
\hline
\end{tabular}

\section{PL Spectra}

Photoluminescence (PL) analysis used to determine the quality of the film and radiative transition between the conduction band and the valance band at room temperature.PL spectra of pure and $\mathrm{Nd}$ doped films at 325 $\mathrm{nm}$ excitation wavelength are displayed in fig 5. In our case, PL Spectrum shows two peaks at 395 and $460 \mathrm{~nm}$. Broad UV emission peak present at $395 \mathrm{~nm}$ corresponds to the sulphur vacancies and the same result was reported by sabitha et al for $\mathrm{Al}: \mathrm{ZnS}$ film [12]. Recombination of electron-hole pairs in zinc vacancies [16] creates high intense visible emission bands at $460 \mathrm{~nm}$. In addition, when $\mathrm{Nd}$ element incorporate with host $\mathrm{ZnS}$ lattice intensity of the visible emission peak changes enormously; which ascribed the population enhancement in host lattice and easiest energy transfer between the band levels [17].

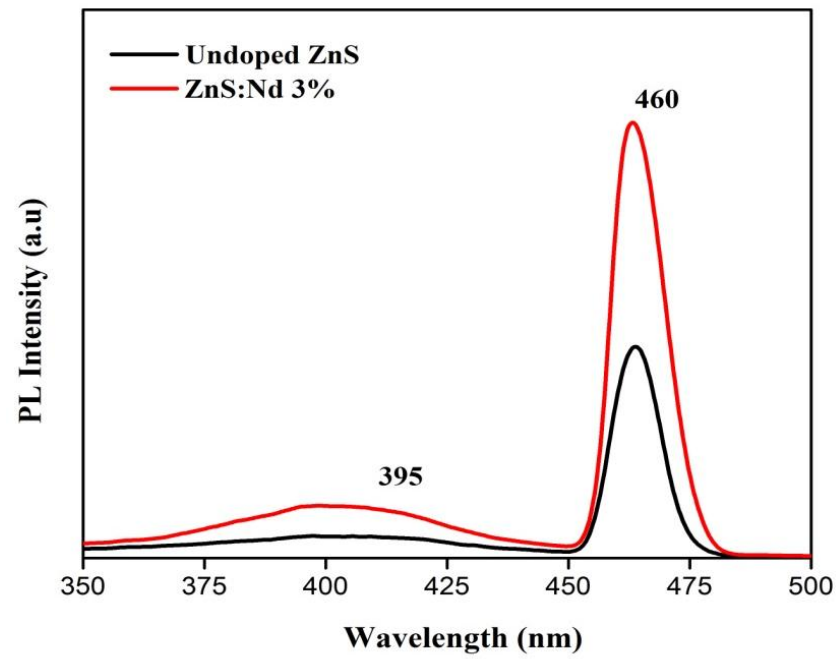

Figure 5. Room temperature PL spectrum of Undoped and 3\% Nd doped $\mathrm{ZnS}$ thin film

\section{CONCLUSION}

Pure and $\mathrm{Nd}$ doped $\mathrm{ZnS}$ thin films were prepared by low cost NSP technique. Polycrystalline with hexagonal structure of the prepared films were evidenced by XRD. Crystalline sizes, micro strain, lattice parameters of the samples were also calculated from XRD data. Particle in the shape of spherically was shown in SEM images. Band gap values of the films were determined by optical studies. High intense, blue Shift of the PL spectrum obtained from the doped film concludes that they are more suitable for creating new kind of luminescence based devices.

\section{REFERENCES}

[1] K. Hirabayashi, K. Ono, "Light Modulation by Applying High Electric Fields in Double-Insulated $\mathrm{ZnS}$ and $\mathrm{ZnSe}$ Polycrystalline Films", Japanese Journal of Applied Physics , Vol 29 Issue.9,L1672, 1990.J. Ruffner, M. Himel, V. Mizrahi, G. Stegeman, and U. Gibson, "Effects of low substrate temperature 
and ion assisted deposition oncomposition, optical properties, and stress of ZnS thin films," J.Appl. Opt. Vol.28,pp 5209-5214 ,1989.

[2] G. Xu, S. Ji, C. Miao, G. Liu, and C. Ye, "Effect of ZnS and CdS coating on the photovoltaic properties of CuInS $S_{2}$-sensitized photoelectrodes" Journal of Materials Chemistry Vol.22,pp 48904896, 2012.

[3] H. Murray, A. Tosser, "Conduction in thin films of r.f. reactively sputtered zinc sulphide", Thin Solid Films, Vol 22, Issue. 1, pp.3744, 1974.

[4] M Izi, G Heidari, S M M Khoie, and J Najafi, "Comparison of ZnS thin films fabricated by electrodeposition and spray pyrolysis methods" Sur Engg and App Elec.chem, Vol 53, Issue. 3, pp 245249, 2017.

[5] J.Ihanus,M.Ritala, M.Leskelä ,T.Prohaska ， R Resch,G. Friedbacher and M. Grasserbauer, " AFM studies on ZnS thin films grown by atomic layer epitaxy", Applied Surface Science Vol 120,pp 43-50, 1997.

[6] F. Gode,, C. Gumus, M. Zora. "Investigations on the physical properties of the polycrystalline $\mathrm{ZnS}$ thin films deposited by the chemical bath deposition method", Journal of Crystal Growth,Vol. 299, pp.136-141, 2007.

[7] J.S. McCloy and B.G. Potter, "Photoluminescence in Chemical Vapor Deposited ZnS: insight into electronic defects," Opt. Mater. Express Vol.3, Issue.9, pp.1273-1278, 2013.

[8] B. Elidrissi, M. Addou, M. Regragui , A. Bougrine , A. Kachouane , and J.C. Bernède, "Structure,composition and optical properties of $\mathrm{ZnS}$ thin films by Spray pyrolysis",Materials Chemistry and Physics Vol. 68, Issue. (1-3),pp.175-179,2001.

[9] C.Y. Tsay, K.S. Fan, C.M. Lei, "Synthesis and characterization of sol-gel derived gallium-doped zinc oxide thin films", Journal of Alloys and Compounds, Vol.512, pp.216-222 2012.

[10] V. Anand, A. Sakthivelu, K.D.A.Kumar, S. Valanarasu, A. Kathalingam, V. Ganesh, MohdShkir, S. AlFaify, I.S. Yahia," Rare earth Sm3+ co-doped AZO thin films for opto-electronic application prepared by spray pyrolysis" Cera.Int,Vol.44, Issue.6, pp.6730-6738, 2018.

[11] C. Sabitha , K.D.A.Kumar, S. Valanarasu , A. Saranya , and I.H Joe," $\mathrm{Cu}: \mathrm{ZnS}$ and $\mathrm{Al}: \mathrm{ZnS}$ thin films prepared on FTO substrate by nebulized spray pyrolysis technique", Journal of Materials Science: Materials in Electronics ,Vol 29, Issue. 6, pp.4612-4623, 2018.

[12] K.D.A Kumar, S Valanarasu, A Kathalingam, K Jeyadheepan, “ $\mathrm{Nd} 3+$ Doping effect on the optical and electrical properties of $\mathrm{SnO} 2$ thin films prepared by nebulizer spray pyrolysis for optoelectronic application",Materials Research Bulletin,Vol. 101, pp.264-271,2018.

[13] C.M. Muiva, T.S. Sathiaraj, K.Maabong, "Effect of doping concentration on the properties of aluminium doped zinc oxide thin films prepared by spray pyrolysis for transparent electrode applications", Ceram.Int, Vol.37, Issue. 2, pp. 555-560, 2011.

[14] A.Goktas,F.Aslan,E.Yasar, and I.H.Mutlu , "Preparation and characterization of thickness dependent nano-structured $\mathrm{ZnS}$ thin films by sol-gel technique", Journal of Materials Science: Materials in Electronics, Vol. 23, Issue. 7, pp 1361-1366, 2012.

[15] AC Dhanya, KV Murali, KC Preetha, K Deepa, AJ Ragina, TL Remadevi, "Effect of deposition time on optical and luminescence properties of $\mathrm{ZnS}$ thin films prepared by photo assisted chemical deposition technique", Materials Science in Semiconductor Processing, Vol. 16, Issue.3, pp. 955-962,2013.

[16] D.Kakoti, NRajkonwar, N.Dehingia, A.Boruah,P.Gogoi and P Dutta, "Effect of $\mathrm{ZnS}$ nanoparticles on the photoluminescence of $\mathrm{Sm}^{3+}$ ions in methanol" , 24th Condensed Matter Days National Conference, Vol 765, Issue. 1, Mizoram, India, 2016.

\section{AUTHORS PROFILE}

Dr. M.Karunakaran is currently working as an Assistant Professor in Department of Physics, Alagappa Government Arts College, Karaikudi. He has published more than 50 research papers in reputed international journals and it's also available online. His main research work focuses on

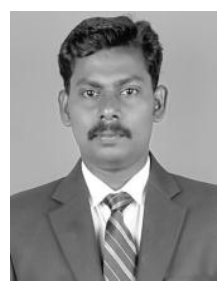
Materials Science (Thin films and Nano materials synthesis) He has 13 years of teaching experience and 10 years of research experience. 